\title{
Article \\ A Four-Level Maturity Index for Hot Peppers (Capsicum annum) Using Non-Invasive Automated Mobile Raman Spectroscopy for On-Site Testing
}

\author{
Robin Legner ${ }^{1,2}$, Melanie Voigt ${ }^{1}$, Carla Servatius ${ }^{1}$, Johannes Klein ${ }^{1}$, Antje Hambitzer ${ }^{3}$ and Martin Jaeger ${ }^{1, * \mathbb{D}}$ \\ 1 Department of Chemistry and ILOC, Niederrhein University of Applied Sciences, Frankenring 20, \\ D-47798 Krefeld, Germany; Robin-Legner@web.de (R.L.); Melanie.voigt@hs-niederrhein.de (M.V.); \\ servatius.carla@posteo.de (C.S.); johannes.klein@stud.hn.de (J.K.) \\ 2 Department of Chemistry, University Duisburg-Essen, Universitätsstraße 2, D-45141 Essen, Germany \\ 3 Office of the Vice President for Research and Transfer, Niederrhein University of Applied Sciences, \\ Reinarzstr. 49, D-47805 Krefeld, Germany; Antje.hambitzer@hs-niederrhein.de \\ * Correspondence: martin.jaeger@hs-niederrhein.de; Tel.: +49-(0)-2151-822-4188
}

\section{check for} updates

Citation: Legner, R.; Voigt, M.; Servatius, C.; Klein, J.; Hambitzer, A.; Jaeger, M. A Four-Level Maturity Index for Hot Peppers (Capsicum annum) Using Non-Invasive Automated Mobile Raman Spectroscopy for On-Site Testing. Appl. Sci. 2021, 11, 1614. https:// doi.org/10.3390/app11041614

Academic Editors: Monica Gallo, Federico Marini and

Alessandra Biancolillo

Received: 17 December 2020

Accepted: 6 February 2021

Published: 10 February 2021

Publisher's Note: MDPI stays neutral with regard to jurisdictional claims in published maps and institutional affiliations.

Copyright: (c) 2021 by the authors. Licensee MDPI, Basel, Switzerland. This article is an open access article distributed under the terms and conditions of the Creative Commons Attribution (CC BY) license (https:/ / creativecommons.org/licenses/by/ $4.0 /)$.

\begin{abstract}
A handheld Raman spectrometer was used to determine the ripeness of peppers. Raman spectra were recorded non-invasively on the fruit surface. The spectroscopic data were transformed into a classification scheme referred to as the maturity index which allowed for attribution of the fruit stadium to four levels from immature to fully mature. Hot pepper and tomato ripening includes pectic polysaccharide depolymerization, chlorophyll degradation and carotenoid formation, among others. The latter were followed non-invasively by Raman spectroscopy. Two portable systems and one benchtop system were compared for their applicability and robustness to establish a suitable maturity index. Spectral acquisition, data treatment and multivariate data analysis were automated using a Matlab script on a laptop computer. The automated workflow provided a graphic visualization of the relevant parameters and results on-site in real time. In terms of reliability and applicability, the chemometric model to determine the maturity of fruits was compared to a univariate procedure based on the average intensity and ratio of three characteristic signals. Portable Raman spectrometers in combination with the maturity index or a chemometric model should be suitable to assess the stage of maturing for carotenoid-containing fruits and thus to determine ripeness on-site or during a sorting process in an automated manner.
\end{abstract}

Keywords: handheld Raman spectrometer; ripening; maturity index; automation; carotenoids; nondestructive sensing

\section{Introduction}

For the determination of the degree of fruit ripeness, no quantitative characteristics or parameters are listed in EU quality standards. However, qualitative characteristics are defined for the fruit-bearing cycle, e.g., the respiration increase or the development of ethylene [1]. To assess fruit development and growth, various parameters such as pulp color and pulp firmness are used [2-5]. Other parameters comprise starch degradation, the Brix value, acidity and the sugar/acid ratio [4]. On a cell-size scale, the depolymerization and size of pectic and hemicellulose polysaccharides were associated with fruit maturation, particularly of tomatoes and hot peppers [6-8]. The determination of these parameters except fruit size and base color can only be achieved by destruction of the fruit, such as homogenization, extraction, staining or labeling, and at the expense of the producer. Fruit ripening is the last phase of fruit development and is associated with increased respiration, which is often accompanied by degradation of chlorophyll and increasing carotenoid content $[9,10]$. A correlation between ethylene and abscisic acid levels at different stages of ripeness was investigated for hot peppers [11]. 
Raman spectroscopy has not been exploited to its full potential in food analysis, although its application is increasing [12]. Raman techniques do not require the laborious pre-treatment described above. Samples can be investigated at ambient temperature and pressure [13]. The technique is fast and non-invasive and portable handheld spectrometers allow spectral recording and testing the fruit on the plant or during sorting. Water has only little or no response, unlike in infrared spectroscopy, such that fresh and dried fruits can be analyzed. The Raman methodology also allows inspecting for food safety through a glass or polymer packaging $[14,15]$.

At the molecular level, one of the starting points of carotenoid synthesis is geranylgeranyl pyrophosphate (GGPP; $\left.\mathrm{C}_{20} \mathrm{H}_{36} \mathrm{O}_{7} \mathrm{P}_{2}\right)[16,17]$. As a first step in this pathway, two GGPP molecules are condensed by phytoene synthase (PSY) into phytoene $\left(\mathrm{C}_{40} \mathrm{H}_{64}\right)[18,19]$. Through desaturation reactions of the enzymes phytoene desaturase (PDS) and $\zeta$-carotene desaturase (ZDS), the characteristic double bonds are formed, which lend the carotenoids their intense color. Finally, the carotenoid cis-trans isomerase (CRTISO) forms the all-trans lycopene, where the synthetic pathway separates. At this point, various lycopene cyclases (LCY) start to produce either $\alpha$ - or $\beta$-carotene [9,20-23]. The different carotenoids have been extensively studied in tomatoes and assigned to stages of ripeness using mobile Raman spectroscopy $[24,25]$. Four to six classes of maturity were described, reflecting the color from green to red [26-28]. The spectroscopic results were interpreted with the help of advanced multivariate data analysis, such as soft independent modeling of class analogy (SIMCA), artificial neural networks (ANN) and partial least squares regression (PLSR), to achieve classification according to maturation. However, similar studies for hot peppers have not been described.

The carotenoid pathway applies to all pepper species as can be recognized by the wellknown color change during maturing. The molecular transformations and the color change do not only occur within the fruit on the plant, but also to already harvested fruit. Green or yellow harvested fruits also turn red when adequately stored and allowed to continue ripening. Since the degree of ripeness is related to the nutrients and to the carotenoid content, Raman spectroscopy is particularly suitable for monitoring of the process [29-34]. It provides good sensitivity to carotenoids and is non-invasive, such that the fruit can continue to evolve after analysis. Handheld or portable spectrometers are suitable for on-site testing without sample preparation [35]. In this study, Raman carotenoid signals typical for hot peppers are described and the signal evolution during maturing is followed. A multivariate chemometric model and a straightforward univariate model are proposed and compared, allowing a four-stage classification of the ripeness of hot pepper fruits.

\section{Materials and Methods}

\subsection{Fruit Samples}

Hot peppers were purchased as pot plants from a local building supplies store (Hornbach, Krefeld, Germany). The plants grew at ambient humidity and temperature, $(22 \pm 3){ }^{\circ} \mathrm{C}$ and $50 \%$ humidity according to laboratory settings. Ambient light conditions were simulated using a Roleadro LED $300 \mathrm{~W}$ plant lamp (Shenzhen Houyi Energy Efficiency Co. Ltd., Shenzhen, China). The lamp emitted red light at 610-615, 620-630 and 650-660 $\mathrm{nm}$ and blue light at 430-440 and 450-470 $\mathrm{nm}$ with a red-to-blue intensity ratio of 4:1. Plants were sufficiently watered at regular intervals. Fruits were either investigated on the plant or picked and sorted according to their current evolution state. For carotenoid evolution monitoring, 21 hot peppers from 1 plant were investigated over a period of 110 days. For spectral intensity variability studies, fruits on plants or harvested were selected accordingly. For principal component analysis (PCA) and maturity index (MI) determination, 122 harvested hot peppers from 4 plants were investigated, yielding a total of 1119 spectra. The tomatoes for comparison were obtained as picked fruits from a local farmer (Carsten Knodt Gemuesebau, Toenisvorst, Germany) and investigated as received. Each of the three stages of ripeness was represented by 10 fruits. The obvious fruit color was noted and used for the referencing of PCA and MI. 


\subsection{Spectroscopy}

Raman spectra were acquired using a handheld Raman (h-RAM) spectrometer, IDRaman mini 2.0 (Ocean Optics, Orlanda, FL, USA). The spectrometer was powered either from a laptop computer or using regular AA batteries. Its weight amounted to $380 \mathrm{~g}$. The h-RAM was equipped with a point-and-shoot adapter (Ocean Optics, Orlanda, FL, USA).Using raster orbital scanning (ROS), the laser beam was moved following a circular pattern with a diameter of $3 \mathrm{~mm}$. The laser beam had a width of approximately $25 \mu \mathrm{m}$. Spectra were acquired from 400 to $2300 \mathrm{~cm}^{-1}$ and the spectral resolution was $13 \mathrm{~cm}^{-1}$. The laser excitation wavelength was $785 \pm 0.5 \mathrm{~nm}$ with a power of $100 \mathrm{~mW}$. As a second instrument, a QE Pro Spectrometer Raman spectrometer (Ocean Optics, Orlando, Fl, USA) was used operating at $638 \mathrm{~nm}$ and $35 \mathrm{~mW}$ with a $638 \mathrm{LAB}$ FCA laser (Ocean Optics, Orlando, FL, USA). An RIP-RPB-638-FC probe was coupled to the spectrometer. The spectra were recorded with a resolution of 7-10 $\mathrm{cm}^{-1}$ and a Raman range of 150 to $3150 \mathrm{~cm}^{-1}$. The software OceanView 1.5.2 (Ocean Optics, Orlando, FL, USA) was used for spectral acquisition. No sample preparation was required when using the two fieldable spectrometers, since both the point-and-shoot adapter and the RIP-RPB-638-FC probe allowed measurements on the fruit by positioning the probe tip close to the fruit surface. The exclusion of ambient light using a blackened cardboard cylinder helped improve the signal intensity.

For comparison, Raman spectra were also recorded on an NXR FT-Raman module (Thermo Scientific, Waltham, MA, USA). The module was connected to a Nicolet 6700 FT-IR spectrometer (Thermo Scientific, Waltham, MA, USA). The spectra were processed using Omnic software version 8.0 (Thermo Scientific, Waltham, MA, USA). For each measurement, 64 spectra were accumulated in the range of 100 to $3800 \mathrm{~cm}^{-1}$. The resolution was set to $6 \mathrm{~cm}^{-1}$. The wavelength of the laser was $1064 \mathrm{~nm}$ with a power of $900 \mathrm{~mW}$. For this benchtop spectrometer, sample preparation required the excision of a part of the hot pepper $(10 \times 10 \mathrm{~mm})$ and positioning it in the spectrometer's sample cell.

\subsection{Data Analysis}

The spectral raw data recorded with the Raman spectrometers were uploaded onto a cloud and imported into Matlab R 2016b (MathWorks, Inc., Natick, MA, USA). Automated spectral processing and preprocessing were applied. Spectral preprocessing was carried out as weighted normalization using the standard normal variate (SNV) using Matlab together with PLS_Toolbox version 8.2.1 for Matlab (Eigenvector Research, Inc., Wenatchee, WA, USA). Spectra were also derivatized. Principal component analysis (PCA) was performed. A number of 3 latent variables were applied, yielding the best results. The singular value decomposition (SVD) algorithm was used for the PCA. Using a home-built Matlab script, the peak intensities of the 3 major Raman bands were identified and used for computing the four-level color-coded maturity index. The results were visualized, allowing instant evaluation after spectral investigation.

\section{Results and Discussion}

\subsection{Detection of Carotenoids by Raman Spectroscopy}

In general, chlorophylls show only very weak Raman responses. Carotenoids, on the other hand, provide very intense Raman signals, so that even small amounts in biological samples such as fruits can be detected. This characteristic feature is important to help detect and compare carotenoid contents in the very early stages of hot pepper maturation. In this respect, only the still completely green hot peppers showed no carotenoid signals at all. In Figure 1, Raman spectra of hot peppers are shown depending on the maturation process of the fruit on the plant. The important and intense carotenoid bands were observed in the range of about 800 to $1600 \mathrm{~cm}^{-1}$. Most bands of green peppers can be assigned to chlorophyll, polysaccharides and waxes, which are present in the cuticular of the fruit. 


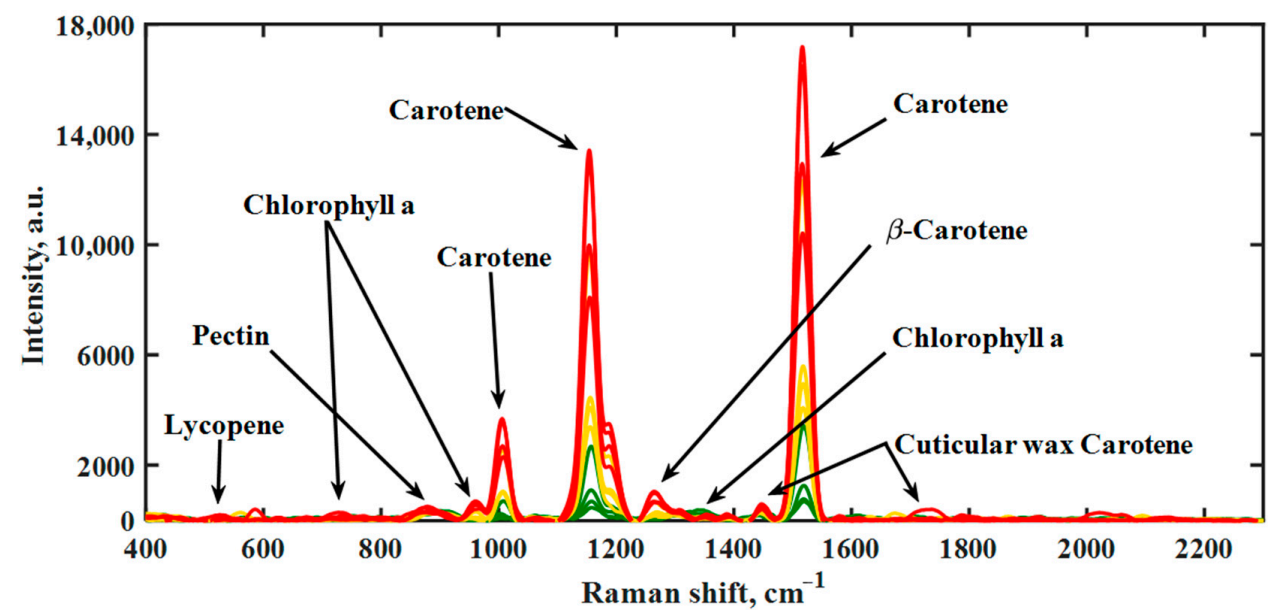

Figure 1. Raman spectra of hot peppers during the maturation process obtained with handheld Raman spectrometer at $785 \mathrm{~nm}$ laser wavelength [13,23,31]. Unripe pepper (green), ripening pepper (yellow) and fully ripe fruit (red) are each represented by four deliberately selected spectra.

The band at about $860 \mathrm{~cm}^{-1}$ could be assigned to a C-O-C asymmetric stretching of the glycoside linkage in acidic pectins $[29,36]$. The weak band at $1327 \mathrm{~cm}^{-1}$ was attributed to chlorophyll a which is known for the highest intensities in a neat chlorophyll spectrum $[10,13]$. The most intense bands in the spectrum were assigned to the carotenoids, observed at $1150-1170$ and $1500-1550 \mathrm{~cm}^{-1}$. The band is due to the in-phase $\mathrm{C}=\mathrm{C}$ as well as C-C stretching vibration of the polyene chain. In the range of $1000-1020 \mathrm{~cm}^{-1}$, methyl groups attached to the polyene chain were recognized, showing moderate intensity [23]. Schulz et al. demonstrated the dependence of a peak shift in the range of 1510-1536 cm on the number of conjugated $\mathrm{C}=\mathrm{C}$ bonds $[10,16,37]$. The complete assignment of the predominant bands in Raman spectra of hot peppers is given in Figure 1.

\subsection{Influence of Excitation Wavelength, Resolution and ROS Technology}

For the automated determination of the ripeness of the fruit, a Raman spectrometer with suitable features should be used; it needs an appropriate excitation wavelength and sufficient resolution paired with the highest possible robustness. Three different Raman spectrometers were used to determine the degree of ripeness of the fruit (for spectral comparison, see Figure 2).

The three characteristic carotenoid signals at 1001, 1156 and $1515 \mathrm{~cm}^{-1}$ were detected using the three spectrometers with laser wavelengths at 638, 785 and $1064 \mathrm{~nm}$. The spectrum with the laser wavelength at $638 \mathrm{~nm}$ suffered from strong fluorescence, so that an extended spectral editing was required. While the fruit surface contains a variety of compounds, the interference stemmed presumably from chlorophylls showing broad absorbance around $662 \mathrm{~nm}$. However, the intensities after background correction remained significantly lower compared to the results of the other two spectrometers. The resolution of the instrument having the laser at $1064 \mathrm{~nm}$ amounted to $6 \mathrm{~cm}^{-1}$ and was much better than that of the handheld instrument. However, it was a benchtop device for laboratory use and was therefore not suitable for field or on-site use. The spectrum recorded with the handheld device having a laser wavelength of $785 \mathrm{~nm}$ displayed more intense signals and an enhanced signal-to-noise ratio as would be expected due to the wavelength dependence of the Raman intensity $\left(\lambda^{4}\right)$. The excitation wavelength was sufficiently red-shifted not to fall within the steeply declining carotenoid absorption in the visible range. The most commonly available $785 \mathrm{~nm}$ Raman laser proved indeed the best choice due to the lack of interference and the most available sensitivity. In addition, the raster orbital scanning technology contributed to improved sensitivity due to averaging over a wider area of the fruit surface [38]. The narrow, focused laser beam followed a circular motion over a larger sample area to yield a better resolution and intensity since an alternating color 
was observed over the fruit surface due to the maturing process, which the raster orbital scanning (ROS) technology took into account better than the sampling technique of the other Raman spectrometers. Thus, the handheld spectrometer was judged more suitable for field use to determine the degree of ripeness. In addition, the spectrometer was coupled directly with a laptop for spectrometer control and evaluation software.

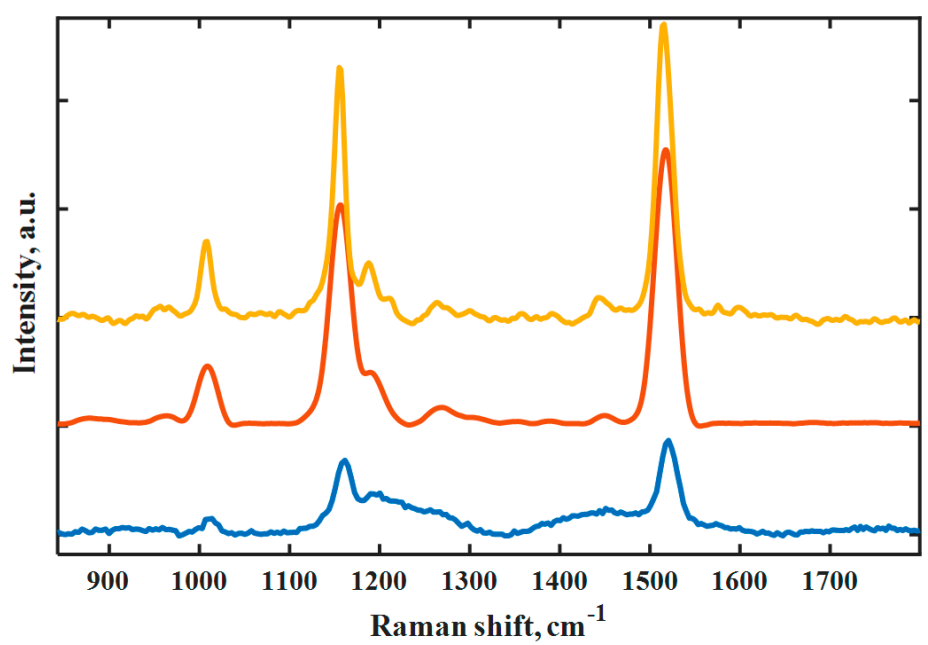

Figure 2. Comparison of the Raman spectra of a hot pepper using instruments with different laser wavelengths. Spectra of mobile spectrometer with laser wavelength at $638 \mathrm{~nm}, 1$ acquisition at 1 spot (blue), handheld spectrometer at $785 \mathrm{~nm}$, ROS with averaging of 1 acquisition each at 10 spots (orange) and benchtop spectrometer at $1064 \mathrm{~nm}, 64$ acquisitions (yellow).

\subsection{Development of Carotenoid Concentration during Maturation}

To assess the maturation level, immature green peppers were monitored over a period of 110 days using Raman spectroscopy. A spot on the surface of the fruits was labeled to ensure measurement at the same position during the observation period. Due to a visible change in color after a few days, a significant increase in the carotenoid signals was expected and found, cf. Figure 3. Over time, the fruit grew fully mature and overripe and dried, and hence carotenoid signals were observed with decreasing intensities.

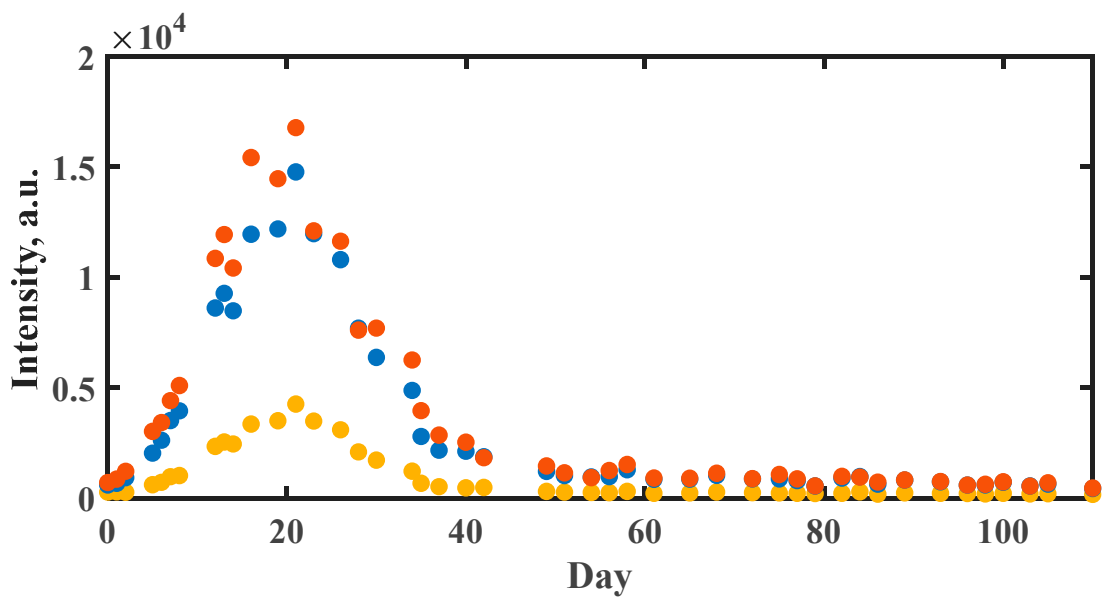

Figure 3. Ripening process of hot peppers as observed through the averaged signal intensity at 1001 (yellow), 1156 (blue) and $1515 \mathrm{~cm}^{-1}$ (orange) in the Raman spectra of three immature, harvested fruits.

There was a clear increase in the three characteristic carotenoid signals after three days. Within the following seventeen days, discoloration of the fruits from green to red occurred. During the remaining days, the characteristic red color persisted, but a 
continuous decrease in the carotenoid bands was observed. From the 50th day onwards, the intensities remained constant at a rather low level. This was traced back to the drying of the fruit and the continuous degradation of the carotene, which preceded and accompanied the fruit deterioration. The long-term experiment demonstrated that the build-up and disintegration of carotenoids could be followed by Raman spectroscopy and that the discoloration from green to red corresponded to a change in the carotenoid levels.

\subsection{Variabilities of the Raman Band Intensities}

Since the maturation process of tomatoes has been studied intensely [30,31,39], 30 hot peppers were compared to the same number of tomatoes. Each species was represented by 10 fruits of the categories immature, maturing and fully matured fruits, see Table 1 . The categories were related to green, orange and red fruits, respectively.

Table 1. Inter-fruit variations of the Raman band intensities at $1500 \mathrm{~cm}^{-1}$ within 10 fruits of each category (green, orange and orange/red, red, see below) and species.

\begin{tabular}{ccccccc}
\hline Species & & Peppers & & & \multicolumn{3}{c}{ Tomatoes } \\
\hline Color & Green & Orange & Red & Green & Orange & Red \\
\hline Mean value & $3.6 \times 10^{2}$ & $2.1 \times 10^{3}$ & $7.5 \times 10^{3}$ & $1.2 \times 10^{2}$ & $3.2 \times 10^{2}$ & $5.5 \times 10^{2}$ \\
Std. deviation & $9.3 \times 10^{1}$ & $2.0 \times 10^{3}$ & $4.9 \times 10^{3}$ & $6.2 \times 10^{1}$ & $1.0 \times 10^{2}$ & $1.9 \times 10^{2}$ \\
Minimum & $2.2 \times 10^{2}$ & $2.8 \times 10^{2}$ & $1.6 \times 10^{3}$ & $2.1 \times 10^{1}$ & $1.6 \times 10^{2}$ & $2.2 \times 10^{2}$ \\
Maximum & $5.9 \times 10^{2}$ & $9.4 \times 10^{3}$ & $1.8 \times 10^{4}$ & $2.3 \times 10^{2}$ & $5.1 \times 10^{2}$ & $1.0 \times 10^{3}$ \\
\hline
\end{tabular}

A comparison of the intensity values revealed a higher carotenoid content within the peppers than within the tomatoes, which might be due to the higher water content of tomatoes, thus a lower carotenoid concentration. The intensity also increased along with the ripening process from green to red. Both green hot peppers and green tomatoes showed low variations within their sample group of 10 . The variations increased significantly during the ripening process. This was explained as due to the fact that fruits of the category orange showed features of different stages of ripeness. The discoloration played an additional role, as the green chlorophyll masked the red carotene and hence led to an obvious lower concentration of the carotene. Hence, the standard deviation of orange and red peppers was almost as large as the mean of all samples in this category.

Since the inter-fruit variation appeared somewhat large, the intra-fruit variability was investigated. Five different measuring locations were defined on single fruits. A ripe pepper was compared with a red tomato, i.e., a ripe tomato, see Table 2. Each test point was examined as a triple measurement using the same parameters.

Table 2. Intra-fruit variations of Raman band intensities at $1500 \mathrm{~cm}^{-1}$ measured as triplicates on 5 spots each on a hot pepper and tomato.

\begin{tabular}{ccc}
\hline Species & Pepper & Tomato \\
\hline Color & Red & Red \\
\hline Mean value & $1.3 \times 10^{4}$ & $6.5 \times 10^{2}$ \\
Std. deviation & $1.8 \times 10^{3}$ & $2.2 \times 10^{2}$ \\
Minimum & $1.1 \times 10^{3}$ & $3.8 \times 10^{2}$ \\
Maximum & $1.8 \times 10^{4}$ & $1.1 \times 10^{3}$ \\
\hline
\end{tabular}

The carotenoid concentration was not found significantly different for the two fruits at the distinct measuring locations. The intra-fruit variation proved comparable to the inter-fruit variation within a color category as shown in Table 1. This is an important finding since an automated analysis would not necessarily have to pay attention and aim for a specific test point. It should hence be sufficient that the laser beam would be focused on an intact area of the fruit surface. For a potential field application, the influence of the 
test location on the fruit surface on the maturity index to be calculated was furthermore verified. Figure 4 shows the results of triple measurements carried out at five points using the handheld spectrometer (blue) and the benchtop spectrometer (orange).

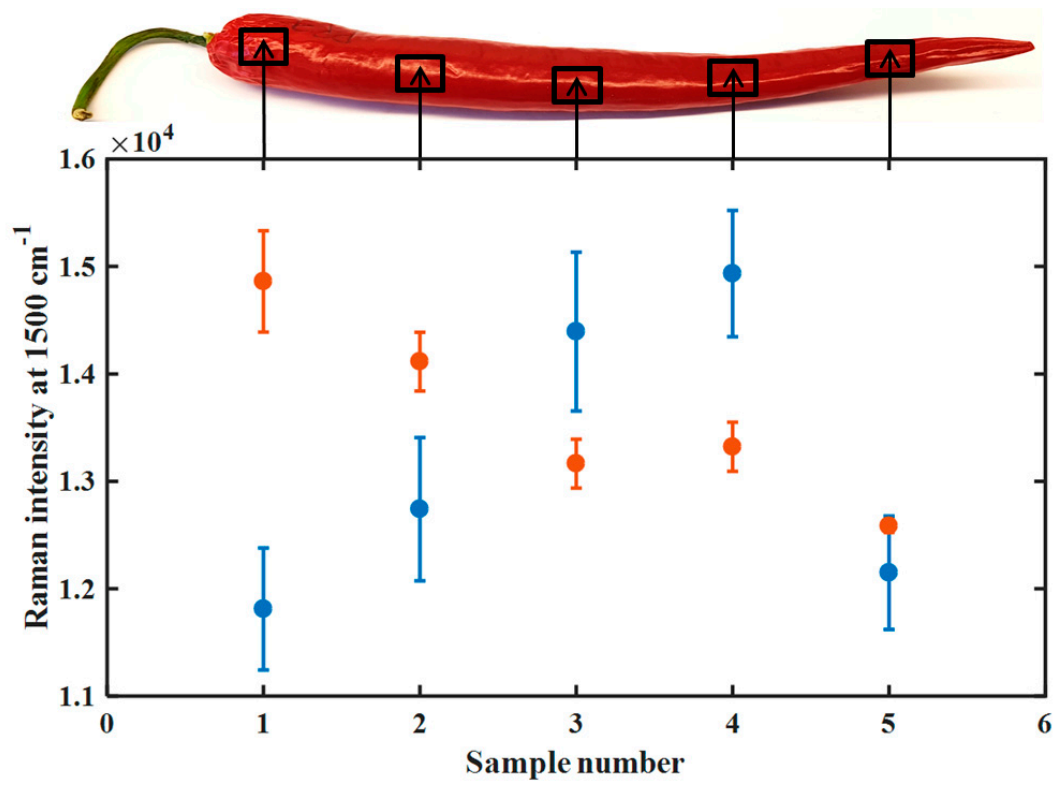

Figure 4. Raman band intensities at $1500 \mathrm{~cm}^{-1}$ and their variation as measured at five spots of a single fully ripe pepper, cf. top picture and marked positions, using the mobile (blue) and benchtop (orange) Raman spectrometers.

Intensities at $1500 \mathrm{~cm}^{-1}$ recorded with the portable Raman spectrometer yield a mean of $13.4 \times 10^{4}$ with moderate variation. The intensities observed in the spectrum of the benchtop spectrometer were slightly higher, although the absolute intensity would not affect the results with respect to the maturity index. Overall, the intensities displayed a lower intra-spot variability of the multiple measurements as indicated by the error bars. The inter-spot variations ranged for both instruments from $1.1 \times 10^{4}$ to $1.6 \times 10^{4}$ at $1500 \mathrm{~cm}^{-1}$, again with a lower variation in the case of the benchtop instrument. Near the stalk, no significantly higher carotenoid concentration was found than at the other measuring points. Inter- and intra-spot variability would greatly influence the results of a field measurement. However, the low variability due to the selection of the test spot position and instrument and the good precision within replicate measurements favor on-site use. It should also be noted that the intra-spot deviation was smaller than the inter-spot variation, as would be expected. Overall, the variations observed with both instruments were in a comparable and acceptable range. The performance of the portable spectrometer seemed sufficient to take advantage of the benefits of portability for field use, e.g., on a plantation.

\subsection{Classification of Pepper Using Principal Component Analysis}

Further, for a visual inspection based on the fruit color, the assessment of the maturity level may be carried out in automated mode, e.g., if an automated sorting was envisaged. Before a quantitative measure of such assessment is established, a qualitative procedure using multivariate data analysis should be presented. To this purpose, principal component analysis (PCA) was chosen, cf. Figure 5. 

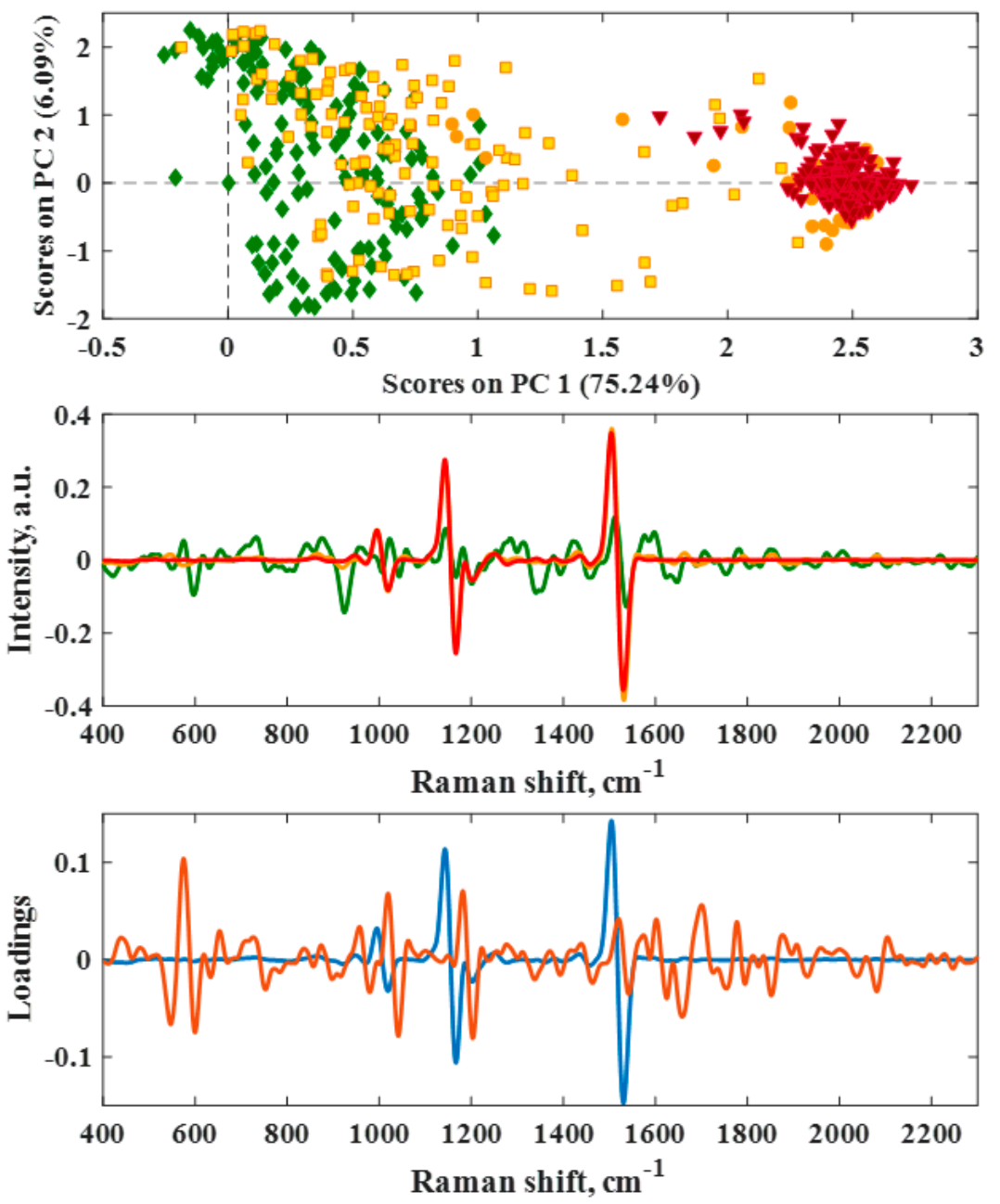

Figure 5. PCA of 1119 spectra from 122 hot pepper samples at different ripeness levels. Top: Scores plot representing the maturity categories fully immature (green spades), immature (yellow squares), harvestable (orange circles) and mature (red triangles). Middle: Averaged preprocessed derivative spectra of immature (green), harvestable (orange) and mature (red) fruits. Bottom: Loading vectors of PC1 (blue, $75.2 \%$ ) and PC2 (orange, 6.1\%).

The scores plot visualizes the 1119 samples labeled according to their maturity category, cf. Table 3. For PCA, preprocessed Raman spectra, i.e., derivative spectra, served as the input matrix. From the representation of the first and second principal components, it can be seen that immature (green) and fully ripe fruit (red) are well separated due to the three major signals, cf. Figure 3. In particular, fully ripe fruits and, to some extent, very immature fruits appear centered on the first component. In contrast, immature and harvestable fruits are spread along the PC1 axis. However, ripening and harvestable fruits (yellow squares and orange circles) are clearly distributed between the early growth and the mature stage. This finding can be interpreted in that ripening fruits still have a higher chlorophyll content and thus are more similar to immature fruits, cf. Figures 1 and 5. From the loading vectors in Figure 5, it can be recognized that the carotenoid level exercises the biggest influence on the spectral and thus ripeness distinction. Chlorophyll and different carotene species are reflected by higher loadings. Determination of the optimum harvest time hence proved difficult when using qualitative PCA. An alternative method might be sought in a univariate method which relies exclusively on the three characteristic carotenoid signals and leads to a quantitative statement on the ripeness of the fruit. 
Table 3. Maturity index values, fruit colors and maturity levels for hot peppers.

\begin{tabular}{|c|c|c|}
\hline Maturity Index & Color & Maturity \\
\hline$<2$ & green & $\begin{array}{c}\text { Fully immature } \\
\text { continued ripening proposed }\end{array}$ \\
\hline $2-3$ & orange & $\begin{array}{c}\text { Immature } \\
\text { significantly lower carotenoid levels than full mature; further plant ripening recommended } \\
\text { Harvestable }\end{array}$ \\
\hline $3-4$ & orange/red & $\begin{array}{c}\text { might reach slightly lower carotenoid contents in the after-ripening than full ripening; } \\
\text { harvest possible, post-maturity recommended }\end{array}$ \\
\hline$>4$ & red & $\begin{array}{l}\text { Fully ripe/mature } \\
\text { suitable for immediate consumption; storage not recommended }\end{array}$ \\
\hline
\end{tabular}

\subsection{Maturity Index}

The intensities of the characteristic carotenoid bands at 1156 and $1515 \mathrm{~cm}^{-1}$ were very similar in all measurement series, cf. Figure 1, while the intensities of the band at $1001 \mathrm{~cm}^{-1}$ appeared with lower intensity but a proportional change referenced to the other two signals. Exemplarily, a fully ripe fruit would show a slightly higher ratio when the intensities of the two bands at higher wavenumbers were very large. Based on the proportional evolution of the signal at $1001 \mathrm{~cm}^{-1}$, the peak intensity ratio was taken as a measure for ripeness. Hence, the level of ripeness could be assessed independent of the absolute value of the obtained intensities. The calculated value is referred to as the color-coded maturity index (MI), with the averaged intensities $I_{x}$ of the signals at $\mathrm{x}=1156$ and $1515 \mathrm{~cm}^{-1}$ and the intensity of the signal at $1001 \mathrm{~cm}^{-1}$ as a reference (see Equation (1)).

$$
\mathrm{MI}=\frac{I_{1156}+I_{1515}}{2 * I_{1001}}
$$

The maturity index is hence dimensionless. As an advantage, the MI allows comparing studies from different Raman spectrometers, since the effect of different intensities due to different laser wavelengths and powers is compensated for.

The maturity index can provide an estimate of the carotenoid level and hence the time of harvest. Previous work on tomatoes reported that harvesting too early might result in lower carotenoid contents, while within this study, no significant differences were observed for green peppers ripening on the plant and for those ripening post-harvest. The calculated maturity index for hot peppers was compared to the fruit color at the time of spectral recording. The values obtained could be assigned to four fruit color classes: green, orange, orange/red and red. During the extensive study, 1109 spectra were recorded from 130 fruits on plants, suggesting that a finer graduation would be possible. An MI between 1 and 2 corresponded to green hot peppers. Reddish green and orange fruits exhibited values with strong variation from 1 to 4 . An MI between 3 and 4 indicated red fruits. Deep red fruits were associated with an index of 4 . Dried nearly brown hot peppers gave rise to values above 4 . It should be noted that a reference system for tomatoes may comprise five or six stages [26,27]. For a feasibility study on hot peppers, an index comprising four levels was considered sufficient. The MI values and assignments to color, ripeness and possible harvest stadiums are listed in Table 3 . The maturity states and possible harvest and storage recommendations were extracted and adopted from literature data mostly on tomatoes.

Unripe peppers possess low amounts of carotenoids. They hence appear green due to the predominant color of chlorophylls. When the fruit turns to orange-red, the color becomes carotenoid-dominated. At this point, fruits may be picked and the evolution proceeds detached from the plant or fruits may proceed ripening on the plant (see above). Analysis of the Raman data revealed similar carotenoid levels for fruits that continued maturing post-harvest and for fruits that continued maturing on the plant. In Figure 6, the calculated maturity index was plotted versus the corresponding sample number of peppers and tomatoes of different maturing stages. The index range can be divided into unripe 
fruits appearing mostly green (green), ripening fruits with a color change from green to orange (orange) and fully ripe fruits colored red to dark red (red).
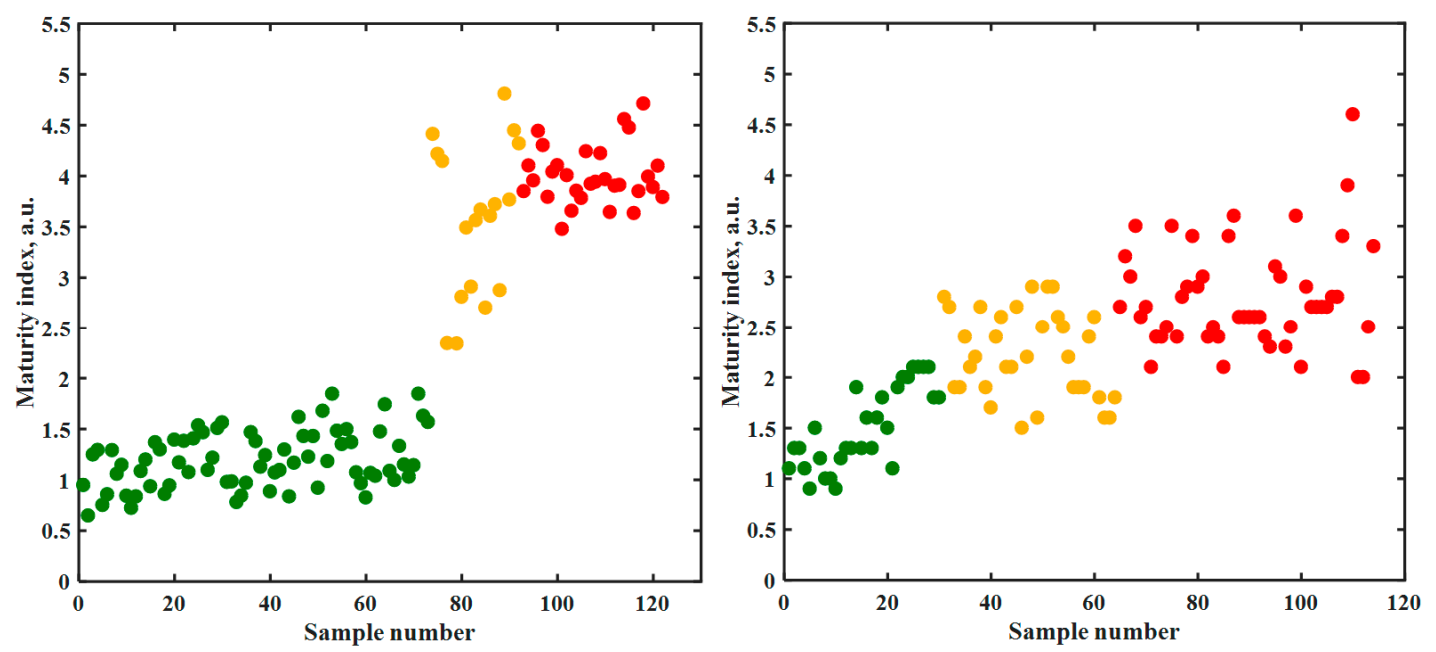

Figure 6. Maturity index for each fruit sample calculated according to equation 1 for hot peppers (left) and tomatoes (right) at different maturity stages. Color coding corresponds to visually perceived green (green), orange to orange/red (orange) and red fruit (red), cf. Table 3.

Immature peppers were associated with a maturity index between 0.5 and 2 . The rather strong variation can again be explained in terms of the low carotenoid and higher chlorophyll content, which gave rise to poor Raman spectra yielding low and hence somewhat noise-afflicted intensity values. The index values of ripening peppers, immature and harvestable, also varied, since at this stage, an uneven carotenoid distribution exists along the fruit and thus inhomogeneous color gradients were perceived. The spectrum and thus the index depended on the investigated spot on the fruit surface. Averaging over several test spots did not reduce the variations to a larger extent, as was shown above. However, a minimum value of about 2.3 could be recognized. Above this value, the analyzed fruits started to display a reddish gloss.

The strong variation within the group of ripening fruits was hence due to the changing colors. Some fruits had a red tip but were green otherwise. However, other fruits exhibited a discoloration in the middle. The fully ripe state (red) was associated with a value of 4 or larger, while the index variation decreased significantly. The variation within this group could be traced back mainly to the aging process of pepper, as some fruits were already overripe.

The lower carotenoid concentrations in tomatoes as compared to hot peppers can be traced back to the higher water content. The Raman intensities observed for both fruit species were therefore different. As a consequence, the tomato maturity index assumed a range different from the one obtained for hot peppers. Tomato fruits seemed immature up to a value of 1.5. Due to the strong uneven discoloration, a similar variability occurred for the ripening tomatoes as for the peppers. Unlike for peppers, a clear distinction between the individual categories could not be recognized, cf. Figure 6 . In summary, the maturity index is specific for one fruit species. Values need to be determined specifically.

Within this study, a total of seven different visual color classes were discerned for hot peppers. As a consequence of the spectroscopic performance, they were reduced to the four categories indicated in Table 3. For tomatoes, no similar detailed classification was achieved in contrast to previous studies [26,27]. Three categories as depicted in Figure 6 were attainable at this level. Again, the ripening fruit stage was the least well defined in terms of the maturity index. The last 14 data points stemmed from overripe tomatoes, which, through the different rotting processes, led to dispersed values of the maturity index. 
While the PCA model distinguished well between ripe and unripe hot peppers but lacked the intermediate stages, one to two ripening categories could be defined using the maturity index. Applying more sophisticated multivariate methods might overcome the disadvantage. The signal variability due to the biological variation in the sample might deteriorate the accuracy of such a chemometric model as well. Hence, the univariate maturity index might be a simple alternative. Raman spectral recording, peak picking, intensity extraction and average ratio computation are easily automated as well as single value comparison to the calibrated index range.

\section{Conclusions}

The non-invasive determination of the maturity index enabled the assessment of the maturation state of hot peppers. Using a handheld Raman spectrometer at $785 \mathrm{~nm}$ laser wavelength, it was possible to investigate the maturation of the fruits. Raman spectra were recorded on the same fruit during ripening and on fruits at different stages of ripeness. Inter-fruit and intra-fruit variations were analyzed as well. Both variations occurred in the same order of magnitude, demonstrating a robust measuring process. For the evaluation, a Matlab script delivered the maturity index directly from the raw spectral data. A fast direct estimate of the maturity state can hence be made on-site, allowing an automated and non-destructive analysis, e.g., in a large greenhouse or at a storing facility. A more detailed view of the fruit color and the discoloration at the measuring point needs to be documented in order to adapt the maturity index for tomatoes. The study suggests that maturity can be identified based on the carotenoid level for fruits other than tomatoes or hot peppers. As a major advantage of Raman spectroscopy over colorimetric studies, valuable information about organic molecules such as carotenoids and chlorophylls associated with the ripening process can be obtained. It should also be possible to further identify the type of carotenoids synthesized in the fruit by more detailed analysis of the Raman shifts.

Author Contributions: Conceptualization, R.L.; methodology, R.L., C.S. and J.K.; software, R.L.; validation, M.V. and M.J.; formal analysis, A.H.; investigation, R.L., C.S. and J.K.; resources, M.J.; data curation, M.V.; writing—original draft preparation, R.L.; writing—review and editing, M.V., A.H. and M.J.; visualization, R.L.; supervision, M.J.; project administration, M.J. All authors have read and agreed to the published version of the manuscript.

Funding: This research did not receive external funding.

Institutional Review Board Statement: Not applicable.

Informed Consent Statement: Not applicable.

Data Availability Statement: The data presented in this study are available on request from the corresponding author. The data are not publicly avaiable due to that Sciebo would not allow. The link would be provided upon request.

Acknowledgments: R. Legner is very grateful for a grant from the German Academic Scholarship Foundation. The authors declare no competing financial interest. We thank C. Knodt for fresh fruits.

Conflicts of Interest: The authors declare no conflict of interest.

\section{References}

1. Bayerische Landesanstalt für Landwirtschaft. Reform der Gesetzgebung zur Vermarktung von Obst und Gemüse; Lerchl-Druck: Freising, Germany, 2009; pp. 1-26.

2. Li, X.; Zhu, X.; Wang, H.; Lin, X.; Lin, H.; Chen, W. Postharvest application of wax controls pineapple fruit ripening and improves fruit quality. Postharvest Biol. Technol. 2018, 136, 99-110. [CrossRef]

3. Obenland, D.; Collin, S.; Sievert, J.; Negm, F.; Arpaia, M.L. Influence of maturity and ripening on aroma volatiles and flavor in "Hass" avocado. Postharvest Biol. Technol. 2012, 71, 41-50. [CrossRef]

4. Coombe, B.G.; Dundon, R.J.; Short, A.W.S. Indices of sugar-Acidity as ripeness criteria for winegrapes. J. Sci. Food Agric. 1980, 31, 495-502. [CrossRef]

5. Tiwari, G.; Slaughter, D.C.; Cantwell, M. Nondestructive maturity determination in green tomatoes using a handheld visible and near infrared instrument. Postharvest Biol. Technol. 2013, 86, 221-229. [CrossRef] 
6. Gross, K.C.; Watada, A.E.; Kang, M.S.; Kim, S.D.; Kim, K.S.; Lee, S.W. Biochemical changes associated with the ripening of hot pepper fruit. Physiol. Plant. 1986, 66, 31-36. [CrossRef]

7. Chylińska, M.; Szymańska-Chargot, M.; Zdunek, A. FT-IR and FT-Raman characterization of non-cellulosic polysaccharides fractions isolated from plant cell wall. Carbohydr. Polym. 2016, 154, 48-54. [CrossRef]

8. Chylińska, M.; Szymańska-Chargot, M.; Deryło, K.; Tchórzewska, D.; Zdunek, A. Changing of biochemical parameters and cell wall polysaccharides distribution during physiological development of tomato fruit. Plant Physiol. Biochem. 2017, 119, 328-337. [CrossRef] [PubMed]

9. Liu, L.; Shao, Z.; Zhang, M.; Wang, Q. Regulation of carotenoid metabolism in tomato. Mol. Plant 2015, 8, 28-39. [CrossRef] [PubMed]

10. Schulz, H.; Baranska, M. Identification and quantification of valuable plant substances by IR and Raman spectroscopy. Vib. Spectrosc. 2007, 43, 13-25. [CrossRef]

11. Hou, B.Z.; Li, C.L.; Han, Y.Y.; Shen, Y.Y. Characterization of the hot pepper (Capsicum frutescens) fruit ripening regulated by ethylene and ABA. BMC Plant Biol. 2018, 18, 162. [CrossRef] [PubMed]

12. Boyaci, I.H.; Temiz, H.T.; Geniş, H.E.; Soykut, E.A.; Yazgan, N.N.; Güven, B.; Uysal, R.S.; Bozkurt, A.G.; Ilaslan, K.; Torun, O.; et al. Dispersive and FT-Raman spectroscopic methods in food analysis. RSC Adv. 2015, 5, 56606-56624. [CrossRef]

13. Baranski, R.; Baranska, M.; Schulz, H. Changes in carotenoid content and distribution in living plant tissue can be observed and mapped in situ using NIR-FT-Raman spectroscopy. Planta 2005, 222, 448-457. [CrossRef] [PubMed]

14. Yang, D.; Ying, Y. Applications of Raman Spectroscopy in Agricultural Products and Food Analysis: A Review. Appl. Spectrosc. Rev. 2011, 46, 539-560. [CrossRef]

15. Qin, J.; Chao, K.; Kim, M.S. Chapter 14: Raman scattering for food quality and safety assessment. In Light Scattering Technology for Food Property, Quality and Safety Assessment; Lu, R., Ed.; Taylor \& Francis: Boca Raton, FL, USA, 2016; pp. $387-428$.

16. Trebolazabala, J.; Maguregui, M.; Morillas, H.; de Diego, A.; Madariaga, J.M. Portable Raman spectroscopy for an in-situ monitoring the ripening of tomato (Solanum lycopersicum) fruits. Spectrochim. Acta-Part A Mol. Biomol. Spectrosc. 2017, 180, 138-143. [CrossRef]

17. DellaPenna, D.; Pogson, B.J. Vitamin Synthesis in Plants: Tocopherols and Carotenoids. Annu. Rev. Plant Biol. 2006, 57, 711-738. [CrossRef]

18. Pedro, A.M.K.; Ferreira, M.M.C. Nondestructive determination of solids and carotenoids in tomato products by near-infrared spectroscopy and multivariate calibration. Anal. Chem. 2005, 77, 2505-2511. [CrossRef] [PubMed]

19. Hirschberg, J. Carotenoid biosynthesis in flowering plants. Curr. Opin. Plant Biol. 2001, 4, 210-218. [CrossRef]

20. Cunningham, F.X.; Gantt, E. Genes and Enzymes of Carotenoid Biosynthesis in Plants. Annu. Rev. Plant Physiol. Plant Mol. Biol. 1998, 49, 557-583. [CrossRef] [PubMed]

21. Isaacson, T.; Ronen, G.; Zamir, D.; Hirschberg, J. Cloning of tangerine from Tomato Reveals a Carotenoid Isomerase Essential for the Production of beta-Carotene and Xanthophylls in Plants. Plant Cell 2002, 14, 333-342. [CrossRef]

22. Misawa, N.; Masamoto, K.; Hori, T.; Ohtani, T.; Boeger, P.; Sandmann, G. Expression of an Erwinia phytoene desaturase gene not only confers multiple resistance to herbicides interfering with carotenoid biosynthesis but also alters xanthophyll metabolism in transgenic plants. Plant J. 1994, 6, 481-489. [CrossRef]

23. Socrates, G. Infrared and Raman Characteristic Group Frequencies, 3rd ed.; John Wiley \& Sons Ltd.: Chichester, UK, 2004; ISBN 978-0-470-09307-8.

24. Hara, R.; Ishigaki, M.; Kitahama, Y.; Ozaki, Y.; Genkawa, T. Use of the product of mean intensity ratio (PMIR) technique for discriminant analysis of lycopene-rich vegetable juice using a portable NIR-excited Raman spectrometer. Food Chem. 2018, 241, 353-357. [CrossRef] [PubMed]

25. Qin, J.; Chao, K.; Kim, M.S. Evaluating carotenoid changes in tomatoes during postharvest ripening using Raman chemical imaging. Sens. Agric. Food Qual. Saf. III 2011, 8027, 802703. [CrossRef]

26. Akpolat, H.; Barineau, M.; Jackson, K.A.; Akpolat, M.Z.; Francis, D.M.; Chen, Y.J.; Rodriguez-Saona, L.E. High-throughput phenotyping approach for screening major carotenoids of tomato by handheld raman spectroscopy using chemometric methods. Sensors 2020, 20, 3723. [CrossRef]

27. Hara, R.; Ishigaki, M.; Kitahama, Y.; Ozaki, Y.; Genkawa, T. Excitation wavelength selection for quantitative analysis of carotenoids in tomatoes using Raman spectroscopy. Food Chem. 2018, 258, 308-313. [CrossRef]

28. Batu, A. Determination of acceptable firmness and colour values of tomatoes. J. Food Eng. 2004, 61, 471-475. [CrossRef]

29. Baranska, M.; Schütze, W.; Schulz, H. Determination of lycopene and $\beta$-carotene content in tomato fruits and related products: Comparison of FT-raman, ATR-IR, and NIR spectroscopy. Anal. Chem. 2006, 78, 8456-8461. [CrossRef]

30. Martin, D.; Gonzalvez, A.G.; Medina, R.M.; González Ureña, A. Modeling Tomato Ripening Based on Carotenoid Raman Spectroscopy: Experimental Versus Kinetic Model. Appl. Spectrosc. 2017, 71, 1310-1320. [CrossRef] [PubMed]

31. Trebolazabala, J.; Maguregui, M.; Morillas, H.; De Diego, A.; Madariaga, J.M. Use of portable devices and confocal Raman spectrometers at different wavelength to obtain the spectral information of the main organic components in tomato (Solanum lycopersicum) fruits. Spectrochim. Acta-Part A Mol. Biomol. Spectrosc. 2013, 105, 391-399. [CrossRef]

32. Qin, Q.; Chen, X.; Zhuang, J. The surface-pore integrated effect of soil organic matter on retention and transport of pharmaceuticals and personal care products in soils. Sci. Total Environ. 2017, 599-600, 42-49. [CrossRef] 
33. Fu, X.; He, X.; Xu, H.; Ying, Y. Nondestructive and Rapid Assessment of Intact Tomato Freshness and Lycopene Content Based on a Miniaturized Raman Spectroscopic System and Colorimetry. Food Anal. Methods 2016, 9, 2501-2508. [CrossRef]

34. Nikbakht, A.M.; Tavakkoli Hashjin, T.; Malekfar, R.; Gobadian, B. Nondestructive determination of tomato fruit quality parameters using Raman spectroscopy. J. Agric. Sci. Technol. 2011, 13, 517-526.

35. Voigt, M.; Legner, R.; Haefner, S.; Friesen, A.; Wirtz, A.; Jaeger, M. Using fieldable spectrometers and chemometric methods to determine RON of gasoline from petrol stations: A comparison of low-field 1H NMR@80 MHz, handheld RAMAN and benchtop NIR. Fuel 2019, 236, 829-835. [CrossRef]

36. Christophe, F.; Séné, B.; Mccann, M.C.; Wilson, R.H.; Crinter, R. Fourier-Transform Raman and Fourier-Transform lnfrared Spectroscopy. Plant Physiol. 1994, 106, 1623-1631. [CrossRef]

37. Schulz, H.; Baranska, M.; Baranski, R. Potential of NIR-FT-Raman spectroscopy in natural carotenoid analysis. Biopolymers 2005, 77, 212-221. [CrossRef]

38. Mattley, Y. High Quality Raman Data for Non-Homogeneous Samples using Raster Orbital Scanning. 2003; Application Note Ocean Optics; pp. 1-3.

39. Qin, J.; Chao, K.; Kim, M.S. Investigation of Raman chemical imaging for detection of lycopene changes in tomatoes during postharvest ripening. J. Food Eng. 2011, 107, 277-288. [CrossRef] 